\title{
Monitoring recent changes in snow cover in Central Asia using improved MODIS snow-cover products
}

\author{
LIU Jinping ${ }^{1,2}$, ZHANG Wanchang ${ }^{1 *}$, LIU Tie $^{3}$ \\ ${ }^{1}$ Key Laboratory of Digital Earth Science, Institute of Remote Sensing and Digital Earth, Chinese Academy of Seiences, \\ Beijing 100094, China; \\ ${ }^{2}$ University of Chinese Academy of Sciences, Beijing 100039, China; \\ ${ }^{3}$ State Key Laboratory of Desert and Oasis Ecology, Xinjiang Institute of Ecology and Geography, Chinese Academy of \\ Sciences, Urumqi 830011, China
}

\begin{abstract}
Snow cover plays an important role in the fields of climatology and cryospheric science. Remotely-sensed data have been proven to be effective in monitoring snow covers, Improved methods to process the 8-day snow-cover products derived from MODIS Terra/Aqua data can dramatically increase the data quality and reduce noise. A five-step algorithm for removing cloud effects was designed to improve the quality of MODIS snow products, and the overall accuracy of the MODIS snow data without cloud (defined as cloud-free snow-cover dataset) was enhanced by more than $90 \%$ based on direct and indirect validation methods. The snow-cover frequency (SCF) and snow-cover rate (SCR) of Central Asia were analyzed from 2000 to 2015 using trend analysis and empirical orthogonal functions (EOFs). Over the plain regions, the SCF displayed a significant north-south declining trend with a rate of 0.03 per degree of latitude, and the SCR showed a similar north-south gradient. In the mountainous areas, the SCF significantly increased with altitude by 0.12 per kilometer. Within the study area, the SCF in $65 \%$ of the study area experienced an increasing trend, but ofly $4.3 \%$ of the SCF-increasing pixels passed a significance test. The remaining $35 \%$ of the area underwent a decreasing trend of SCF, but only $5.2 \%$ of the SCF-decreasing pixels passed a significance test. For the entire Central Asia, the inter-annual variations of snow-cover presented a slight and insignificant increase trend from 2000 to 2015 . However, the change trends of snow cover are different between the plain and mountainous regions. That is, the annual mean SCR in the plain areas displayed an indreasing trend, but a decreasing trend was found in the mountainous
\end{abstract} areas.

Keywords: snow-cover; MODIS; cloud-removing; empirical orthogonal function; Central Asia

Citation: LIU Jinping, ZHANG Wanchang, LIU Tie. 2017. Monitoring recent changes in snow cover in Central Asia using improved MODIS snow-cover products. Journal of Arid Land, 9(5): 763-777. doi: 10.1007/s40333-017-0103-6

\section{Introduction}

In the context of the climate warming studies, the snow-cover variation in the regional scale is of a great significance for local water resources management (Tekeli et al., 2005; Wang et al., 2008). More than $50 \%$ of the land areas in Northern Hemisphere is covered by snow in winter (Barry, 2008; Brutel-Vuilmet et al., 2013) and both the extent and duration of seasonal/perennial snow cover have been affected by global climate change (Brown et al., 2010). The long-term variations of snow cover at different spatial and temporal scales have become one of the hotspots in climate change studies (Dietz et al., 2013; Tang et al., 2013). Since snow-cover variations are directly 
associated with snow-runoff processes, it is essential to accurately monitor snow cover for predicting snowmelt water-resulted floods and water snowmelt water resources (Yang et al., 2007; Brutel-Vuilmet et al., 2013; Dietz et al., 2013).

Snow-cover mapping has been conducted in many regions and most efforts were devoted to mapping snow-cover extent (SCE) (Foppa et al., 2004; Liang et al., 2008). Although traditional in-situ measurements can provide high-precision snow depth observations, it is impossible to map the spatial variability of snow-cover rate (SCR) and snow-cover frequency (SCF) at large spatial scales (Gafurov and Bárdossy, 2009). With the advantages of remote sensing technologies, many studies on snow-cover mapping have employed Landsat (Crawford et al., 2013), SPOT (Dankers and De Jong, 2004), the advanced very high resolution radiometer (AVHRR; Foppa et al,, 2004), the moderate resolution imaging spectroradiometer (MODIS; Liang et al., 2008), and the Special Sensor Microwave/Imager (SSM/I; Foster et al., 2009) and so on. Among them, Landsat and SPOT can provide data with high spatial resolution but relatively low temporal resolution while SSM/I has high temporal resolution but low spatial resolution $(>25 \mathrm{~km})$. Existing studies also showed that snow-cover products derived from AVHRR data using the algorithm of normalized difference snow index (NDSI) have poor performance in bad weather conditions (Maurer et al., 2003; Wang et al., 2005). The MODIS sensors are considered as an appropriate data source with a spatial resolution of $500 \mathrm{~m}$ and a daily temporal resolution. Its high overall accuracy (93\%) in SCE mapping under clear-sky conditions is another advantage (Hall and Riggs, 2007; Wang et al., 2008). Furthermore, MODIS 8-day snow-cover products of MOD10A2 and MYD10A2 can provide higher accuracy on both snow and land (i.e., snow-free area) than MODIS daily products (Hall et al., 2002). However, the accuracy is dramatically reduced under the cloudy weather conditions for both daily and 8-day snow-cover products (Tekeli et al., 2005). It has been reported that approximately $99 \%$ of the MOD10A1 products is composed of $10 \%$ of cloud cover pixels. For the MOD10A2 products, the corresponding value was 14\% during 2001 and 2005 (Liang et al., 2008). The purpose of this study is to explore the spatial and temporal characteristics of the snow-cover variations in Central Asia over the period 2000-2015 using a five-step cloud removal algorithm based on MODIS 8-day snow-cover products, and to validate the reliability of the five-step approach for removing the cloud effects.

\section{Study area and data}

\subsection{Study area}

The study area, Central Asia $\left(35^{\circ}-55^{\circ} \mathrm{N}, 45^{\circ}-95^{\circ} \mathrm{E}\right.$; Fig. 1), includes Xinjiang Uygur Autonomous Region of China and five central Asian countries: Kazakhstan, Uzbekistan, Kyrgyzstan,

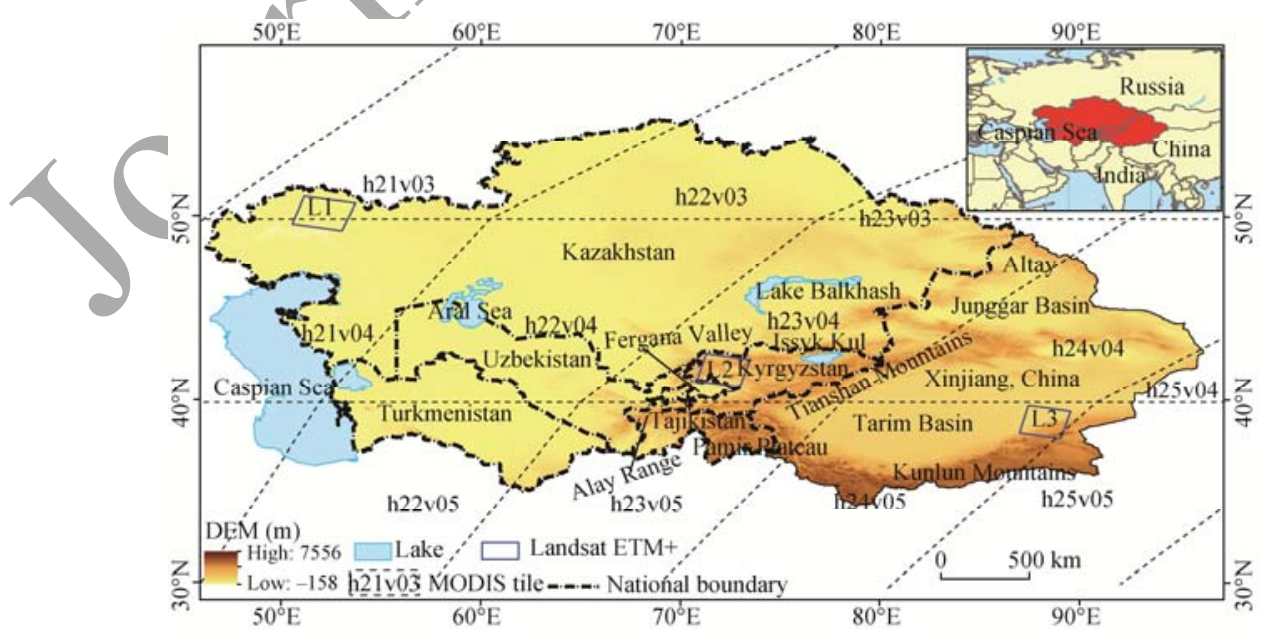

Fig. 1 Overview of Central Asia with MODIS tile grids (parallelograms shown as dashed lines) and major lakes (blue polygons). Data source for administrative information was cited from $\mathrm{Hu}$ et al. (2014), and the locations of lakes were obtained from ArcGIS 10.2. 
Turkmenistan and Tajikistan. It covers an area of approximately $5.6 \times 10^{6} \mathrm{~km}^{2}$ and extends to the Caspian Sea to the west and the Gobi deserts of China to the east, Russia to the north, and Pakistan, Iran and Afghanistan to the south. The mountainous regions are mainly situated in the southeastern Central Asia and account for about $17.3 \%$ of the total area. The Kunlun Mountains, Pamir Plateau, Tianshan Mountains, and Altay Mountains are considered as the mountainous regions.

Most part of Central Asia are dominated by typical temperate continental arid and semi-arid climate. Only southeastern Pamir Plateau belongs to alpine climate (Lioubimtseva and Henebry, 2009; Yin et al., 2016). The western and northwestern plain regions are open to cold northerly and northwesterly air inflows and also influenced by westerly moist influx from the North Atlantic. The southeastern mountainous regions e.g., Pamir Plateau, Tianshan Mountains, and Kunlun Mountains) are almost completely isolated from the moist air masses originating from the Indian Ocean. Therefore, the spatial distribution of precipitation shows strong gradients from north to south and also from mountains to lowlands (Lindzen and Nigam, 1987; Liu et al., 2010). For the entire Central Asia, the snowfall events mainly occur from the preceding November to succeeding April in one hydrological year (from 1 September to 31 August next year).

\subsection{Data}

The 8-day snow products MOD10A2 (V005) and MYD10A2 (V005) (Hall et al., 2001) provided by the National Snow and Ice Data Center (NSIDC) were selected to generate the time series of cloud-free and high-accuracy snow-cover dataset to characterize the spatial and temporal variations of snow cover in Central Asia. For one hydrological year, there are 46 scenes of snow-cover data. NDSI values were used to identify snow pixels with a series of threshold values (Hall et al., 2002). Eleven categories of pixel cover types are listed in Table 1.

Table 1 Pixel cover types of the MOD10A2 and MYD10A2 products

\begin{tabular}{cccc}
\hline Pixel value & Pixel cover types & Pixel value & Pixel cover types \\
\hline 0 & Missing data & 50 & Cloud \\
1 & No decision & 100 & Lake ice \\
11 & Night & 200 & Snow \\
25 & Land without/snow cover & 254 & Detector saturated \\
37 & Lake & 255 & Fill \\
39 & Ocean & & \\
\hline
\end{tabular}

Altitude information was required for the cloud removal algorithm and the analyses of snow-cover variations. We adopted the Digital Elevation Model data with the spatial resolution of $90 \mathrm{~m}$ (Version 4.0) derived from SRTM (Wang et al., 2008). The data are of global coverage and can be downloaded from the website, http://srtm.csi.cgiar.org.

Three Landsat ETM+ scenes with cloud coverage less than 5\% and 30-m spatial resolution (Fig. 1) were selected to represent one plain (L1) and two mountainous (L2 and L3) regions for validating the accuracy of the cloud-free snow-cover dataset. More details are shown in Table 2. The preprocessing of Landsat ETM + data, including radiometric calibration and atmospheric corrections, were implemented in ENVI software.

Table 2 Information of the Landsat ETM + data for validation

\begin{tabular}{cllccc}
\hline Scene & Sensor & Imaging time & Path & Row & Cloud coverage (\%) \\
\hline L1 & ETM+ & 19 Nov, 2014 & 167 & 25 & 2 \\
L2 & ETM+ & 28 Dec, 2014 & 152 & 31 & 1 \\
L3 & ETM+ & 15 Dec, 2014 & 141 & 33 & 5 \\
\hline
\end{tabular}

Additionally, global ecological regionalization data with 867 ecological regions (derived from National Earth System Science Data Sharing Infrastructure, National Science \& Technology Infrastructure of China) were implemented in this study. In Central Asia, we selected the key ecological regions for plain regions (Badghyz and Karabil (BK) semi-desert, southern Central 
Asian (SCA) desert, northern Central Asian (NCA) desert, Kazakh semi-desert, Kazakh steppe, Kazakh upland, and Kazakh forest steppe) and for mountainous regions (Kunlun Mountains, Pamir Plateau, Tianshan Mountains, and Altay Mountains) to investigate the difference of SCR and variations among these regions.

\section{Methodology}

\subsection{Cloud removal}

Although the MODIS 8-day products have better quality than the daily products (Zhou et a1., 2005; Ault et al., 2006; Wang et al., 2008), it is still not realistic to apply the data directly without removing the cloud-covered pixels. The cloud cover is the major obstacle influenceing the accuracy of the analytical results (Zhou et al., 2005; Hall and Riggs, 2007). Wang et al. (2008) reported a mean accuracy of $19 \%$ as the winter cloud mask used in MOD10A2 in northern Xinjiang of China. In this study, a five-step algorithm was designed to estimate the snow status of the cloud-covered pixels.

The first step combines Terra (MOD10A2) and Aqua (MYD10A2) satellite data observed at different times on the same day (Wang and Xie, 2009) to obtain the maximum SCR, and the overall accuracy of this step is $92 \%$ (Dietz et al., 2013). The second step is to spatially combine the four directly "side-bordering" neighboring pixels of the cloud-covered pixels A cloud-covered pixel is defined as a snow-covered pixel when three of its four directly neighboring pixels are snow. The overall accuracy of this method is $92.38 \%$ (Gafurov and Bárdossy, 2009). The third step involves integrating the environmental lapse rate of temperature variations along the altitude gradients. If the eight neighboring pixels are cloud-free, the center pixel that was covered with clouds will be examined. The accuracy of this step can reach 94\% (Gafurov and Bárdossy, 2009). The fourth step, proposed as the Snowl algorithm by Parajka et al. (2010), is intended to eliminate cloud-covered pixels at extremely low or high altitude. The basic concept is to calculate the minimum and maximum altitude of snow-covered pixels. Based on the altitude of the upper snow line, the cloud-covered pixels are assigned as snow when they are above the upper snow line but are assigned as land when below the lower snowline. The accuracy of this step can reach 95\% (Parajka et al., 2010). The fifth step is designed to further check the snow-covered pixels based on the daily status of each pixel in one hydrological year. It is important to note that the dataset of Eight Day Snow Cover Chronology (EDSC) contained in the MOD10A2 and MYD10A2 is also needed to obtain daily snow-cover status of each pixel. The overall accuracy of this step is higher than $78 \%$ (Gafurov and Bárdossy, 2009; Dietz et al., 2013).

\subsection{Validation of the cloud-free snow-cover dataset}

To obtain reliable assessment of snow-cover variations, accurate evaluation of the cloud-free snow-cover dataset is essential for the utilization of the datasets. However, it is rather difficult to conduct in-situ measurements in these regions. Therefore, we applied indirect methods to validate the cloud-free snow-cover dataset in this study. The indirect validation method was proposed by Gafurov and Bárdossy (2009) and improved by Dietz et al. (2013). The overall accuracy depends on two factors: the overall accuracy under clear-sky conditions and the inherent accuracy of the algorithm. Previous studies suggested that the accuracy of cloud-free pixels in MOD10A2 can reach $93 \%$ under clear-sky conditions. The overall accuracy of algorithms can be estimated by the weighted average accuracy based on the accuracy of algorithm adopted in each step. The overall accuracy of the cloud-free snow-cover dataset thus can be calculated by Equation 1 .

$$
\begin{aligned}
& T_{\mathrm{ai}}=\left[\left(\text { Pixel }_{\text {clear-sky }} \times 93 \%+\text { Pixel }_{\text {step } 1} \times 92 \%+\text { Pixel }_{\text {step } 2} \times 92.38 \%\right.\right. \\
& \left.\left.+ \text { Pixel }_{\text {step } 3} \times 94 \%+\text { Pixel }_{\text {step } 4} \times 95 \%+\text { Pixel }_{\text {step } 5} \times 78 \%\right) / T_{\mathrm{p}}\right] \times 100 \%,
\end{aligned}
$$

where $T_{\text {ai }}$ denotes the overall accuracy of the cloud-free snow-cover dataset under the indirect validation method, and $T_{\mathrm{p}}$ is the total number of pixels in a given dataset. Pixels represents the 
number of cloud-covered pixels that were removed.

A direct validation method was employed to further validate the reliability of the cloud-free snow-cover dataset,. Firstly, we obtained snow-cover maps through visual interpretation of Landsat ETM+ data in the selected cloudless regions. The snow-cover maps derived from Landsat ETM+ and cloud-free 8-day snow-cover dataset were referred to as SCM-ETM+ and SCM-MODIS, respectively. Through the intersection tool in ArcGIS, we obtained the common snow area $\left(\mathrm{C}_{\text {snow }}\right)$ and common land area $\left(\mathrm{C}_{\text {land }}\right)$ between SCM-ETM+ and SCM-MODIS. Additionally, the snow area and land (i.e., snow-free) area in SCM-ETM+ were referred to as $\mathrm{T}_{\text {snow }}$ and $\mathrm{T}_{\text {land }}$, respectively, which were considered as the truth value to validate the overall accuracy as Equation 2:

$$
T_{\text {ad }}=\left(\frac{C_{\text {snow }}+C_{\text {land }}}{T_{\text {snow }}+T_{\text {land }}}\right) \times 100 \%,
$$

where $T_{\text {ad }}$ denotes the overall accuracy of the cloud-free snow-cover dataset under the direct validation method.

\subsection{Spatio-temporal snow-cover variations}

The cloud-free snow-cover dataset, which was processed by the five-step approach to remove the effects of the cloud and validated through the direct and indirect validation methods, was adopted to analyze the spatial and temporal variability over the period 2000-2015. The snow-cover frequency $(\mathrm{SCF})$ is defined by Equation 3.

$$
S C F=\sum S_{(x, y)} / N,
$$

where $N$ is the total number of images for cloud-free snow-cover dataset in one hydrological year, and $S_{(x, y)}$ is the status of pixel cover types. When this index is 1 , it indicates that the pixel is covered by snow, and 0 indicates non-snow-covered pixels.

The SCR is defined as the percentage of snow-covered area in a single 8-day image data $S_{\text {area }}$ to the total area of Central Asia $T_{\text {Area }}$ in Equation 4.

$$
S C R=\left(S_{\text {area }} / T_{\text {area }}\right) \times 100 \%,
$$

where $S_{\text {area }}\left(\mathrm{km}^{2}\right)$ stands for the area of snow cover in a single 8-day image, and $T_{\text {Area }}\left(\mathrm{km}^{2}\right)$ is the total area of Central Asia. A 5-year running mean and the corresponding confidence interval were calculated to further examine the trend of the SCR during the 15 hydrological years,.

\subsection{Anomaly detection}

Empirical orthogonal function (EOF) was employed to analyze the anomaly field of the snow-cover frequencies (SCFs) in the spatial and temporal dimensions. A small set of uncorrelated variables, instead of the original information produced by linear transformation for data dimensional reduction, was applied in this method (Xu et al., 2009). This method is widely used for multivariable analysis in meteorology, geology, and geography (Ryu and Jenkins, 2005) with clear advantages of no need for specific functional form, fast convergence rate and powerful information enrichment capability, and decomposing stationary data with an irregular distribution over finite regions (Singh, 2004). It is necessary to analyze the characteristics of the eigenvectors, especially when the number of actual points in space is larger than samples. The actual physical meanings of these eigenvectors can be determined using the method proposed by North et al. (1982), and the errors $\delta \lambda_{i}$ of eigenvalue $\lambda_{i}$ can be estimated by Equation 5 .

$$
\begin{aligned}
& \delta \lambda_{i} \cong \lambda_{i} \sqrt{\frac{2}{N}}, \\
& \Delta \lambda_{i}=\left|\lambda_{i}-\lambda_{i-1}\right|,
\end{aligned}
$$

where $N$ stands for the number of samples, and $\lambda_{i}$ denotes the $i^{\text {th }}$ eigenvalues. $\lambda_{i}$ and $\lambda_{i-1}$ represents the latter and the former eigenvalues, respectively. If $\delta \lambda_{i} / \Delta \lambda_{i}$ is less than 1 , the difference between 
these two eigenvalues is greater than the errors, implying that $\lambda_{i}$ and $\lambda_{i-1}$ are fairly well separated.

Additionally, in a specific EOF mode, the positive (negative) anomaly denotes above (below) the average value of SCR during 2000-2015 in this study.

\subsection{Characteristics of snow-cover variations in different ecological regions}

Based on the ecological regionalization data, we investigated the fluctuating characteristics of the mean SCR every 8 d during 2000-2015 over the different ecological regions (plain and mountainous regions). Furthermore, the seven ecological regions of plain regions were divided into three latitude levels (i.e., low-latitude regions, mid-latitude regions, and high-latitude regions) to clarify the characteristics of snow-cover variations with latitude. Meanwhile, the characteristics of snow-cover variations over four mountainous regions were also analyzed. Eventually, the inter-annual variations of SCR over plain regions with different elevation bends and mountainous regions (Pamir Plateau, Tianshan Mountains, Kunlun Mountains, and Altay Mountains) were investigated using linear least square method during 2000-2015.

\section{Results}

\subsection{Accuracy of the cloud-free snow-cover data}

Three MODIS tiles were selected to represent the plain (h21v03) and the mountainous regions (h23v04 and h24v05) to validate the accuracy of the cloud-free snow-cover data. These scenes in Figure 2 were randomly selected from two hydrological years (2003/2004 and 2014/2015) after



Fig. 2 Diagrams of the monthly average overall accuracy vs. the percentage of the processed pixels in each step of the five-step algorithm for the tiles of the plain (h21v03) and the mountainous areas (h23v04 and h24v05) in $2003 / 2004$ and 2014/2015 
cloud removal. Bars represent the percentage of pixels processed by each step in cloud removal algorithm, and the curves are the monthly average overall accuracy of the cloud-free dataset. The accuracies of the second and third steps in the cloud removal algorithm were combined because a notably smaller percentage of the pixels was processed compared with the other steps.

It can be seen that the cloud-covered pixels are mainly removed by the first step that combines the Terra and Aqua data and the fourth step that employs the Snowl algorithm. The two steps accounted for at least $30 \%$ of the cloud-covered pixels, and the maximum fraction of cloud-covered pixels (92.38\% in h21v03) was removed in May of 2003/2004. Generally, the overall accuracies of the three MODIS reference tiles (h21v03, h23v04 and h24v05) fall in the range of $90 \%-94 \%$.

For the three reference tiles in each month, the overall accuracy of the cloud-free dataset ranges from $92.79 \%$ to $93.34 \%$, and the accuracy in winter is slightly lower than those in other seasons. The annual mean accuracy of the cloud-free dataset in the plain areas $(93.01 \%)$ is slightly higher than that in mountainous areas $(92.97 \%)$. The overall accuracy of the cloud-free dataset is consistently greater than $92 \%$ throughout the selected year, even in December 2003 when cloud coverage reached the maximum (approximately 40.8\%).

As complementary of indirect validation method, the direct validation method is also performed. Figure 3 shows the comparison between SCM-ETM+ and SCM-MODIS, including the false color composite image derived from Landsat ETM+ using bands 5, 4, and 3 (Figs. 3a-1, a-2, and a-3), the spatial distribution of snow cover through visual interpretation based on Landsat ETM+ (Figs. 3b-1, b-2, and b-3), and the cloud-free snow-cover dataset based on MODIS (Figs. $3 \mathrm{c}-1, \mathrm{c}-2$, and c-3). A relatively good consistency is observed between the snow-cover maps. Through the application of Equation 2, we obtained the overall accuracy of the cloud-free snow-cover dataset (Table 3). The overall accuracies of SCM-MODIS were greater than $90 \%$ in both the plain and the mountainous regions. But, the SCM-MODIS in the plain region (L1) showed a slight higher accuracy than that in the mountainous regions (L2 and L3), being consistent with the conclusion obtained from the indirect validation method.

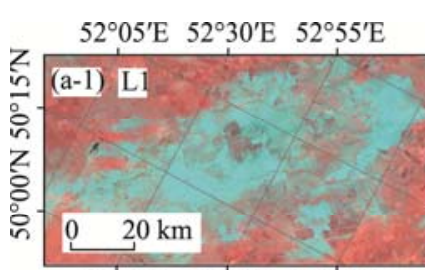

$52^{\circ} 30^{\prime} \mathrm{E} 52^{\circ} 55^{\prime} \mathrm{E} \quad 53^{\circ} 20^{\prime} \mathrm{E}$

$71^{\circ} 40^{\prime} \mathrm{E} \quad 72^{\circ} 05^{\prime} \mathrm{E} \quad 72^{\circ} 30^{\prime} \mathrm{E}$

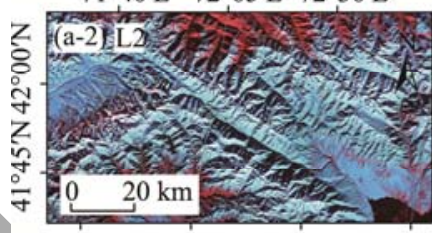

$71^{\circ} 40^{\prime} \mathrm{E} \quad 72^{\circ} 05^{\prime} \mathrm{E} \quad 72^{\circ} 30^{\prime} \mathrm{E} 72^{\circ} 55^{\prime} \mathrm{E} 71^{\circ} 40^{\prime} \mathrm{E} 72^{\circ} 05^{\prime} \mathrm{E} \quad 72^{\circ} 30^{\prime} \mathrm{E} 72^{\circ} 55^{\prime} \mathrm{E} 71^{\circ} 40^{\prime} \mathrm{E} \quad 72^{\circ} 05^{\prime} \mathrm{E} 72^{\circ} 30^{\prime} \mathrm{E} \quad 72^{\circ} 55^{\prime} \mathrm{E}$

$87^{\circ} 55^{\prime} \mathrm{E} 88^{\circ} 20^{\prime} \mathrm{E} 88^{\circ} 45^{\prime} \mathrm{E} 89^{\circ} 10^{\prime} \mathrm{E} 87^{\circ} 55^{\prime} \mathrm{E} 88^{\circ} 20^{\prime} \mathrm{E} 88^{\circ} 45^{\prime} \mathrm{E} 89^{\circ} 10^{\prime} \mathrm{E} 87^{\circ} 55^{\prime} \mathrm{E} 88^{\circ} 20^{\prime} \mathrm{E} 88^{\circ} 45^{\prime} \mathrm{E} 89^{\circ} 10^{\prime} \mathrm{E}$
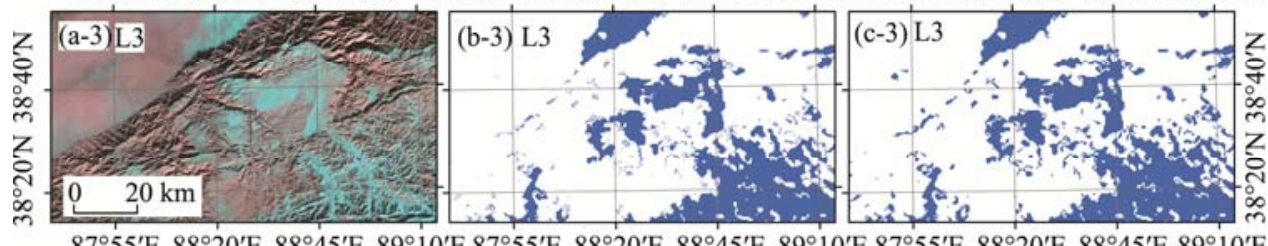

$87^{\circ} 55^{\prime} \mathrm{E} 88^{\circ} 20^{\prime} \mathrm{E} 88^{\circ} 45^{\prime} \mathrm{E} 89^{\circ} 10^{\prime} \mathrm{E} 87^{\circ} 55^{\prime} \mathrm{E} 88^{\circ} 20^{\prime} \mathrm{E} 88^{\circ} 45^{\prime} \mathrm{E} 89^{\circ} 10^{\prime} \mathrm{E} 87^{\circ} 55^{\prime} \mathrm{E} 88^{\circ} 20^{\prime} \mathrm{E} 88^{\circ} 45^{\prime} \mathrm{E} 89^{\circ} 10^{\prime} \mathrm{E}$

Fig. 3 A comparison of snow-cover maps obtained through visual interpretation of Landsat ETM $+\left(2^{\text {nd }}\right.$ column $)$ and through cloud removal of MODIS 8-day snow-cover products $\left(3^{\text {rd }}\right.$ column). Left to right: false color composite image derived from Landsat ETM+ using bands 5, 4, and 3 (a-1, a-2, a-3), snow-cover maps obtained through visual interpretation of Landsat ETM+ (b-1, b-2, b-3), and snow-cover maps obtained through the removal of clouds from the MODIS 8-day snow-cover products (c-1, c-2, c-3). 
Table 3 Results comparison between SCM-ETM+ and SCM-MODIS

\begin{tabular}{cccccc}
\hline Scene & $\mathrm{C}_{\text {snow }}\left(\mathrm{km}^{2}\right)$ & $\mathrm{C}_{\text {land }}\left(\mathrm{km}^{2}\right)$ & $\mathrm{T}_{\text {snow }}\left(\mathrm{km}^{2}\right)$ & $\mathrm{T}_{\text {land }}\left(\mathrm{km}^{2}\right)$ & $\mathrm{T}_{\text {ad }}(\%)$ \\
\hline L1 & 2495.11 & 4530.26 & 2506.78 & 5058.77 & 92.86 \\
L2 & 6941.32 & 1239.12 & 7026.56 & 1989.68 & 90.73 \\
L3 & 2473.50 & $10,059.53$ & 2502.60 & $11,124.70$ & 91.97 \\
\hline
\end{tabular}

Note: $C_{\text {snow }}$, common snow area; $C_{\text {land }}$, common land area; $T_{\text {snow }}$, snow area and land (i.e., snow-free) area in SCM-ETM+; $T_{\text {ad }}$, overall accuracy of the cloud-free snow-cover dataset under the direct validation method.

\subsection{Spatial and temporal variations of snow cover}

We generated a mean SCF map for Central Asia during the study period (Fig. 4a) based on the cloud-free snow-cover dataset of Central Asia. In general, the SCF in the plain regions was lower than that in the mountainous regions; the perennial snow cover accounted for only approximately $0.34 \%$ of the study area and mainly distributed in the Pamir Plateau, the Alay Range (Fig. 1), and the middle/eastern Tianshan Mountains. In general, The SCF is dependent on altitude.

Profile lines (Fig. 4), which were inspired by Dietz et al. (2013), can be used to analyse the SCF variations along a geographical gradient. Profile line 1 (Fig. 4b) exhibits a typical distribution of the SCF with a north-south gradient, revealing that the SCF decreased with decreasing latitude at a
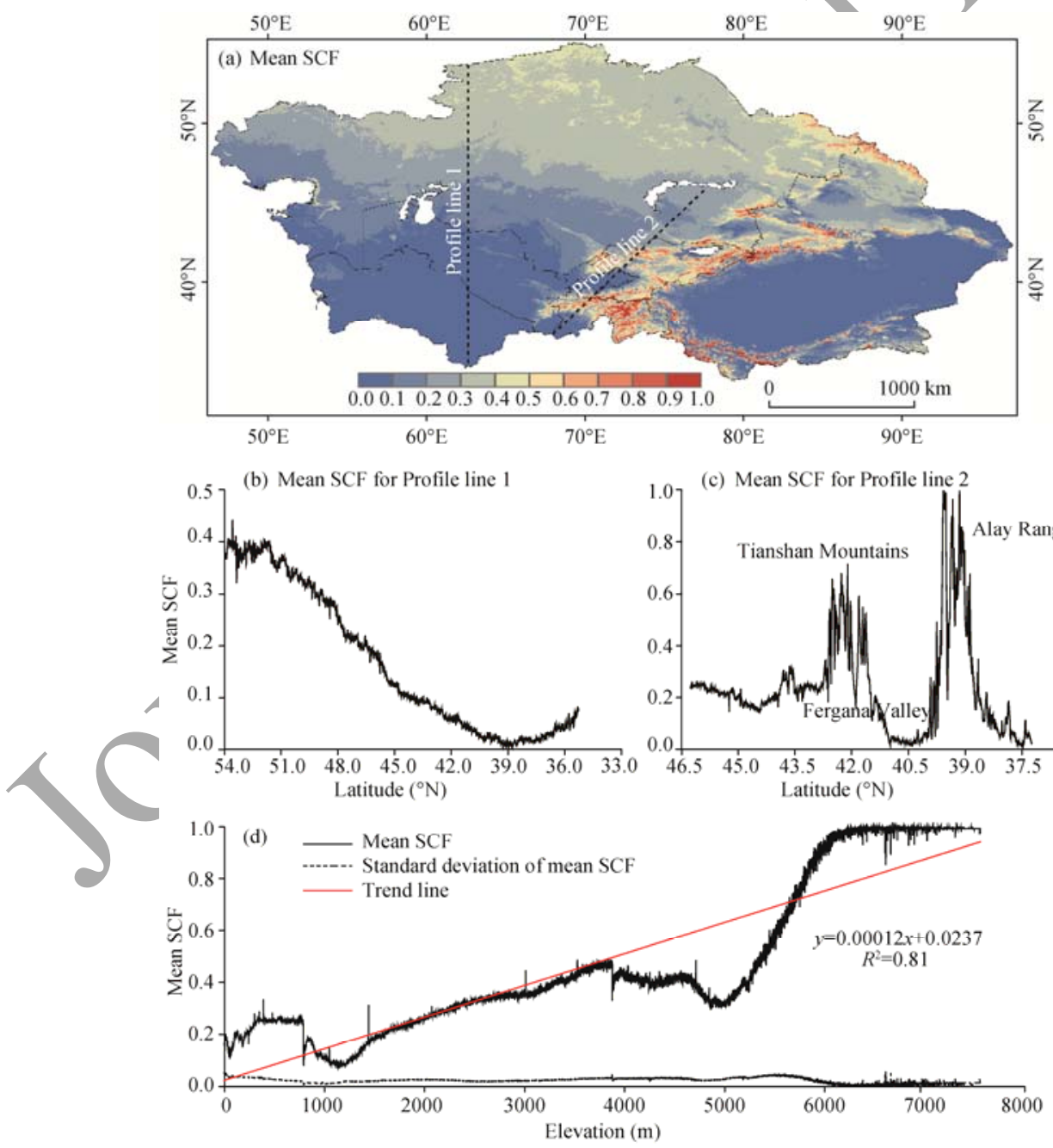

Fig. 4 Spatial distribution of the annual mean snow-cover frequency (SCF) derived from the snow-cover frequencies from 2000/2001 to 2014/2015 (a), annual mean SCF changes with latitude in the plain regions (Profile line 1, b) and mountainous regions (Profile line 2, (c)), and the linear relation between annual mean SCF and altitude (d) 
rate of approximately 0.03 per degree in latitude $\left(R^{2}=0.97, P<0.001\right)$ between $39^{\circ} \mathrm{N}$ and $54^{\circ} \mathrm{N}$. However, a slight increasing trend was observed with a rate of 0.015 per degree in latitude $\left(R^{2}=0.85, P<0.001\right)$ between $35^{\circ} \mathrm{N}$ and $39^{\circ} \mathrm{N}$.

Profile line 2 (Fig. 4c) is drawn across mountainous regions (Tianshan Mountains and Alay Range) and the intermontane Fergana Valley. Along this line (i.e., line 2), the SCF did not vary with latitude. Rather, it increased with increasing altitude (Yatagai et al., 2012).

For the entire Central Asia, a strong correlation between the mean SCF and altitude was found with a rate of approximately 0.12 per kilometer $\left(R^{2}=0.81, P<0.001\right.$; Fig. $\left.4 \mathrm{~d}\right)$ and the strongest SCF's dependency on altitude occurs between 4000 and $6000 \mathrm{~m}$ in the Kunlun Mountains and the eastern Pamir Plateau.

\subsection{Inter-annual variations of snow cover}

Figure 5 presents the temporal variations of the mean SCR and SCF. The SCR exhibits a slight and insignificant increasing trend $\left(R^{2}=0.07, P=0.36\right.$; Fig. 5a), suggesting that the mean snow-cover extent in Central Asia has not changed significantly during the study period. The SCF also showed a slight insignificant increasing trend $\left(R^{2}=0.12, P=0.21\right.$; Fig. $\left.5 \mathrm{~b}\right)$, also suggesting that the SCF has not changed significantly during the study period.
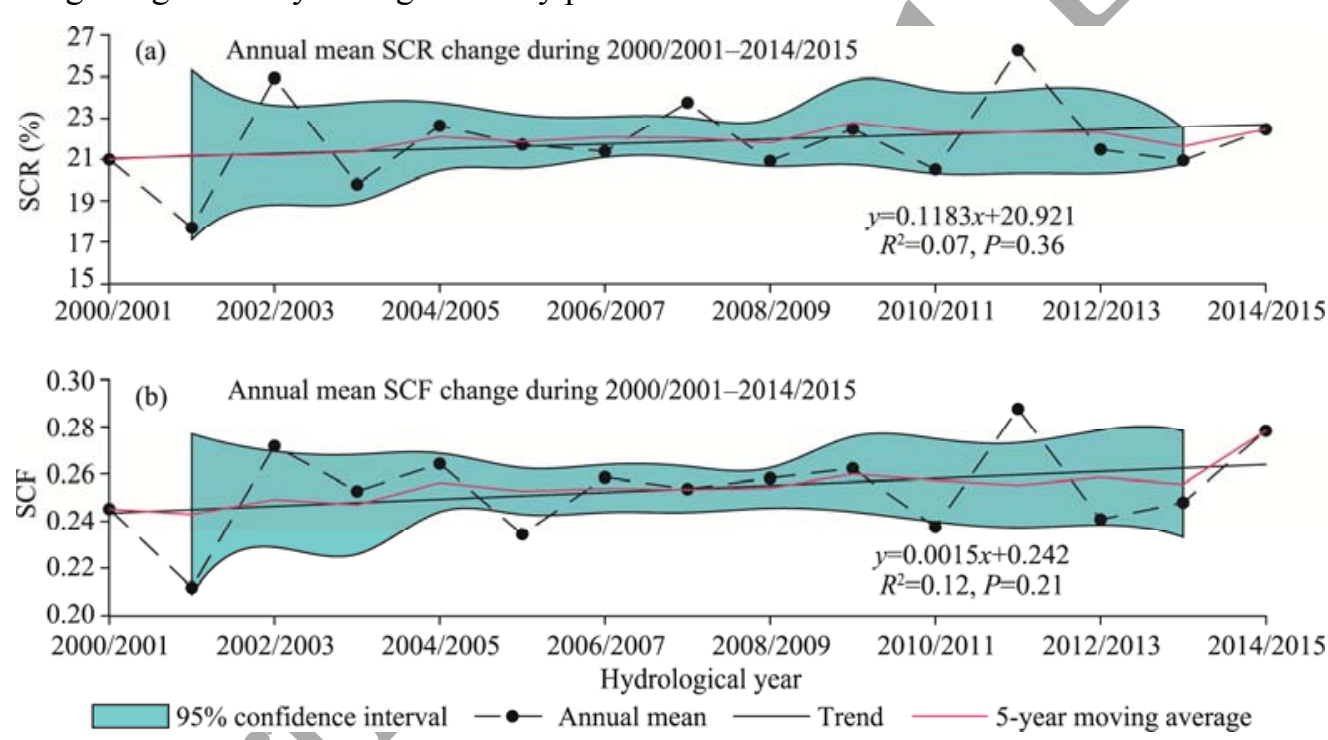

Fig. 5 Changes in annual mean snow-cover rate (SCR; a) and annual mean SCF (b) over Central Asia from $2000 / 2001$ to $2014 / 2015$

Figure 6 illustrates the spatial distribution of the slope of SCF (Fig. 6a) and the corresponding $P$ values (Fig. 6b). It can be seen that the majority of Central Asia (approximately $65 \%$ of the total pixels) experienced an increase of SCF. But, only $4.3 \%$ of these SCF-increasing pixels is statistically significance and they were distributed in western and central-southern Kazakhstan and northwestern and southern Turkmenistan. By contrast, about $35 \%$ of Central Asia underwent a decrease in SCF, of which $5.2 \%$ of the area had a significant decrease. The significant decrease mainly occurred in western Tarim Basin and southern and eastern Xinjiang of China. The SCF tended to increase in most of the plain areas (e.g., Kazakhstan, Uzbekistan and Turkmenistan), although the increasing trend was not statistically significant.

\subsection{Anomaly detection for snow-cover variations}

EOF analysis was employed to detect the spatial and temporal variations of snow cover using a small number of variables (Table 4). The first two EOF modes (EOF-1 and EOF-2) represented the predominant change patterns and contributed $39.95 \%$ of the spatial anomaly variability. These first two modes were thus selected to analyze the anomaly variations of snow cover to reveal the main physical processes behind the snow-cover variations in Central Asia. 
The first mode EOF-1 (Fig. 7a) exhibits the SCF variation with positive or negative anomalies in $27.65 \%$ of the total variance. Positive anomalies account for $77.5 \%$ of the total pixels, mostly in western and southern Kazakhstan. The remaining 22.5\% reflects the negative anomalies predominately distributed in the Pamir Plateau, Tianshan Mountains, Kunlun Mountains, Altay Mountains, and northeastern Xinjiang in China. The positive anomalies in SCF variability exceed 2.0 for some pixels, whereas the negative anomalies are mostly lower than 1.0. The corresponding orthogonal time coefficients (Fig. $7 \mathrm{~b})$ tend to increase although insignificantly $\left(R^{2}=0.14, P=0.16\right)$. However, it is noteworthy that the SCF anomaly variability is significant in the years of 2001/2002 and 2011/2012 at a significance level of 0.05 , being correspondent to the results suggested in Figure 5b. All these analyses confirm that the majority of Central Asia experienced an increase in SCF during the study period. However, in western and southern Kazakhstan, about $35 \%$ of the area underwent a decrease in SCF. It mainly occurred in the mountainous areas.

Table 4 Eigenvalues $\lambda$, variance contributions $R$, and the results of the North test $\delta \lambda / \Delta \lambda$ for the EOF analyses

\begin{tabular}{ccccccc}
\hline EOF analysis & EOF-1 & EOF-2 & EOF-3 & EOF-4 & EOF-5 & EOF-6 \\
\hline$\lambda\left(10^{-4}\right)$ & 9.43 & 4.20 & 3.17 & 2.29 & 2.07 & 2.04 \\
$R(\%)$ & 27.65 & 12.30 & 9.31 & 6.71 & 6.08 & 5.99 \\
$\delta \lambda / \Delta \lambda$ & - & 0.29 & 1.14 & 0.15 & 0.17 & - \\
\hline
\end{tabular}

Note: EOF, empirical orthogonal function; numbers with the acronym EOF represent EOF modes 1-6.

EOF-2, which contributes $12.30 \%$ of the total variance, displays a strong contrast between high latitude/mountainous regions and low-latitude/basin regions in SCF. That is, positive anomalies of SCF occurred in low-latitude regions including southern/Kazakhstan, Uzbekistan, Turkmenistan, and Tarim Basin (Fig. 7c), whereas negative anomalies were found in northern Kazakhstan and most mountainous areas with high latitude or altitude. In addition, the fluctuations of the time coefficients corresponding to EOF-2 were close to the central value of 0 (Fig. 7d), suggesting that the SCF anomalies revealed by EOF-2 were representative.

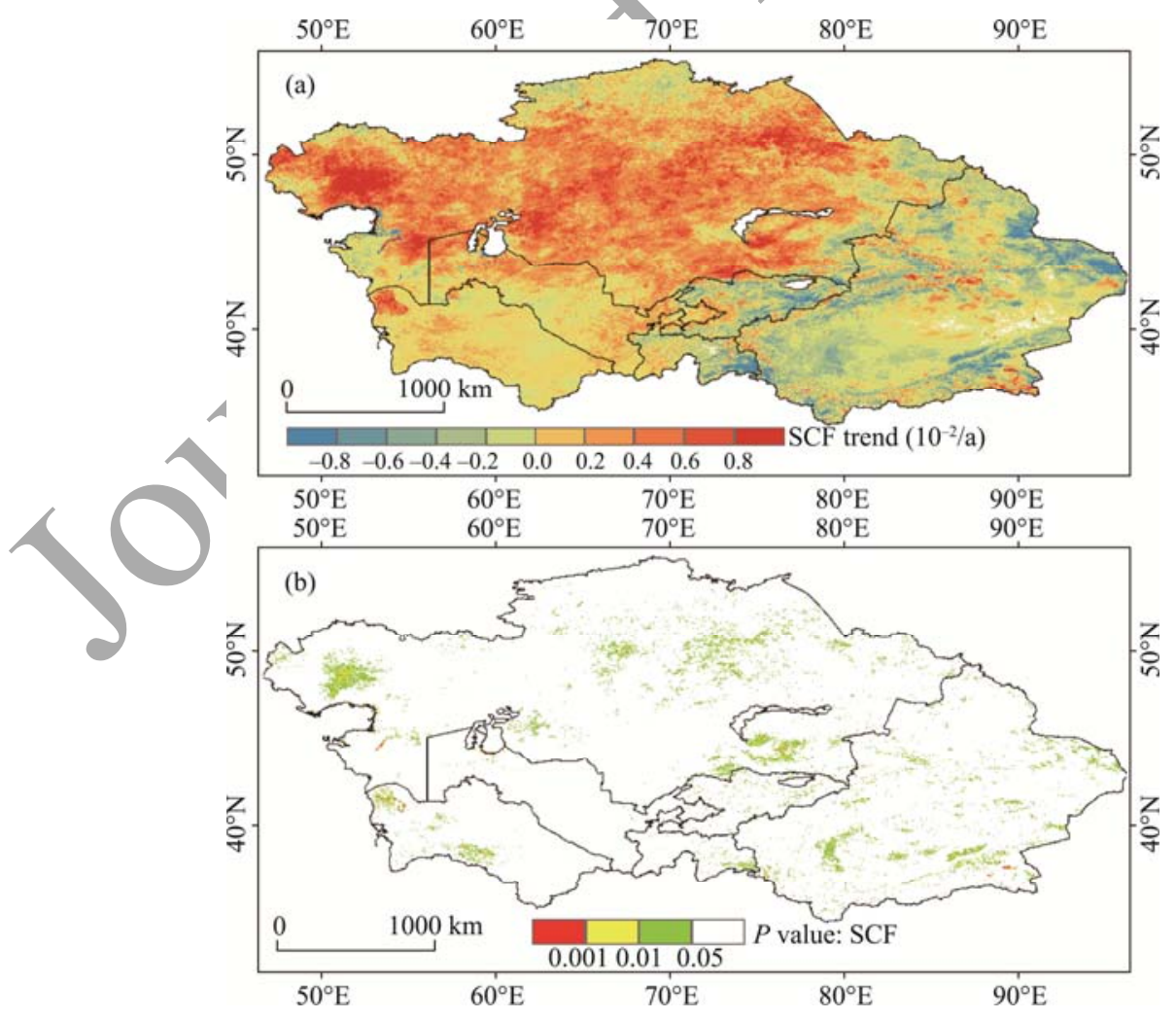

Fig. 6 Spatial change trends in the SCF (a) and the statistical $P$ values associated with the spatial change trends in the SCF (b) in Central Asia during the period 2000/2001-2014/2015 

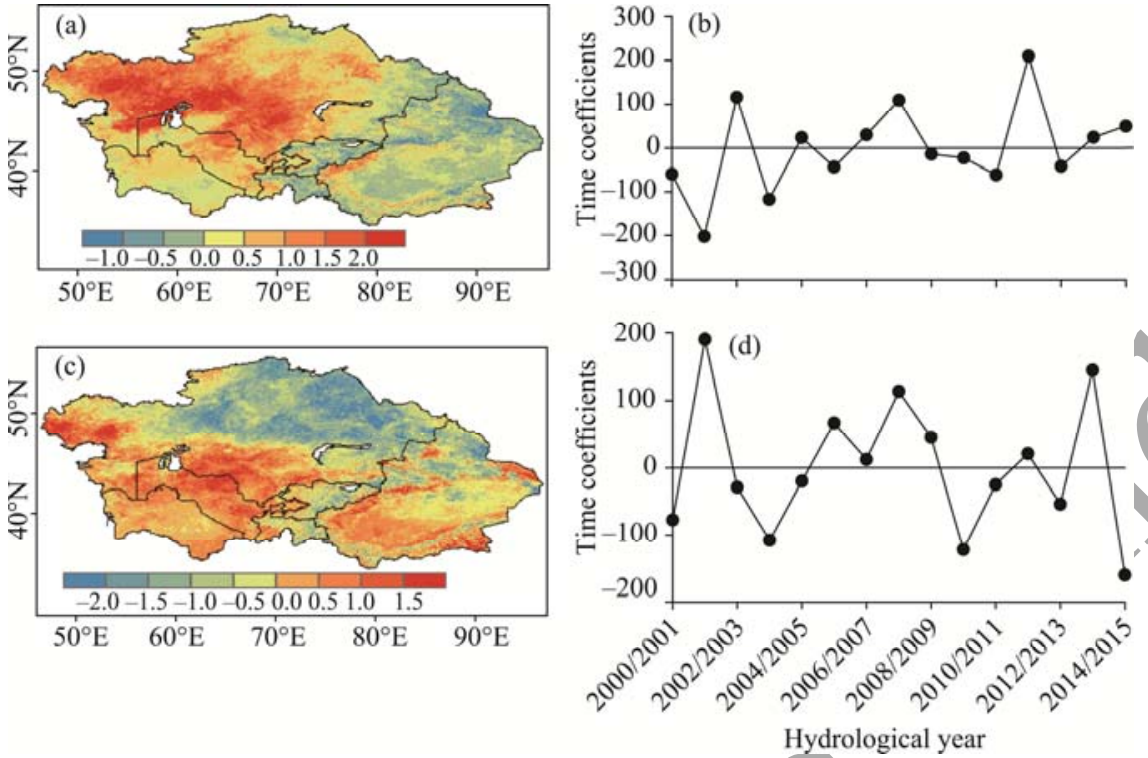

Fig. 7 Empirical orthogonal function model 1 (EOF-1) of the annual SCF anomalies (a) and the corresponding time series of EOF-1 (b) and EOF-2 of the annual SCF anomalies (c) and the corresponding time series of EOF-2 (d)

\subsection{Characteristics of snow-cover variations in different ecological regions}

Since the spatial distribution of snow cover also correlates with the ecological regions, the ecological regions in Central Asia are further divided into plain and mountainous regions (Fig. 8). The snow-cover variations in the different plain regions (Fig. 9a) indicated that they were robustly and positively correlated with latitude. According to the characteristics of snow-cover variations in the plain regions, the seven ecological/regions located in the plain regions were divided into the low-latitude regions (consisting of the BK semi-desert and the SCA desert), the mid-latitude regions (consisting of the NCA desert and the Kazakh semi-desert), and the high-latitude regions (consisting of the Kazakh steppe, Kazakh upland, and Kazakh forest steppe) to further investigate the characteristics of snow cover. In winter (Julian day 337 to 57), the SCR (snow-cover rate) in the low-latitude, mid-latitude, and high-latitude regions ranges from $3.41 \%$ to $26.84 \%$, from $38.29 \%$ to $73.54 \%$, and from $83.15 \%$ to $99.60 \%$, respectively. At the same time, the snow-cover duration prolonged with the increasing latitude in the plain areas. The SCR variation in the mountainous regions (Fig. 9b) also shows a similar latitudinal dependency.

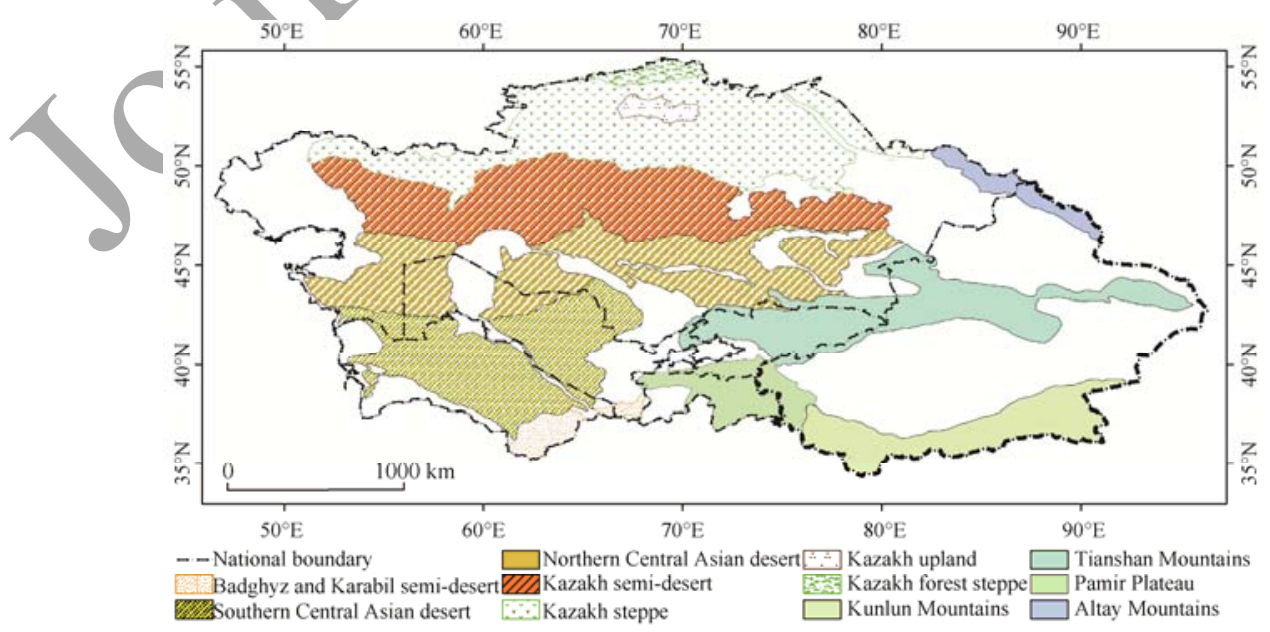

Fig. 8 Spatial distribution of the key ecological regions in Central Asia 




$249265281297313329345361009025041057073089105121 \quad 137 \quad 153169185201217233$

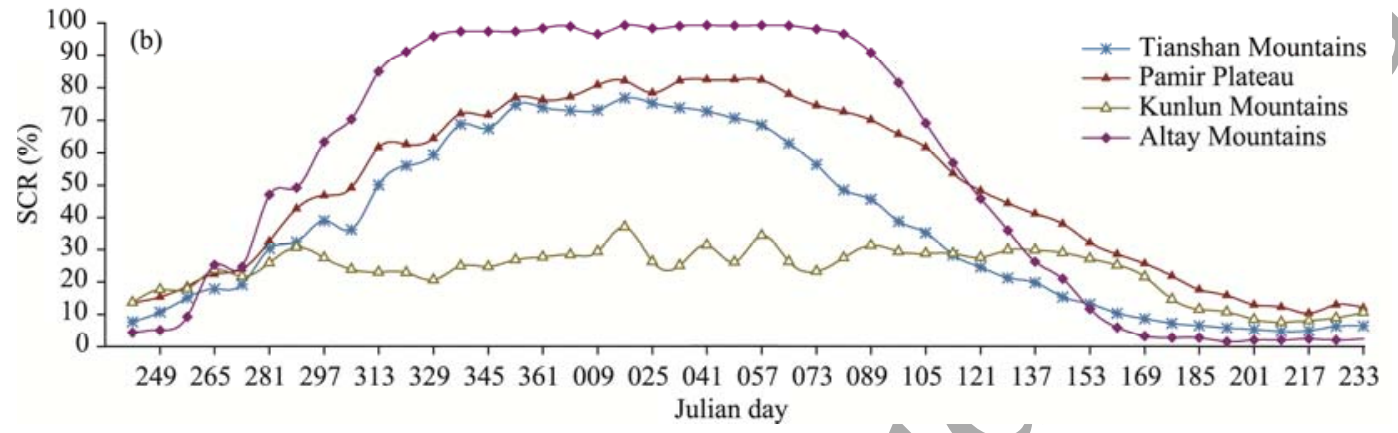

Fig. 9 Dynamic variations of the mean SCR in the different ecological regions during the period 2000-2015 for the plain areas (a) and the mountainous areas (b)

To further investigate the characteristics of snow cover in the different ecological regions, we computed the annual mean SCR (Fig. 10). The mean SCR variations in the low-latitude, mid-latitude, and high-latitude regions of the plain areas during the past 15 years indicated that SCR increases with the increasing latitude. The inter-annual variation of SCR in the mountainous areas suggests that Altay Mountains had the maximum SCR during the period 2000-2015, followed by Pamir Plateau, Tianshan Mountains, and Kunlun Mountains, suggesting that SCR increases with increasing latitude in the mountainous areas.
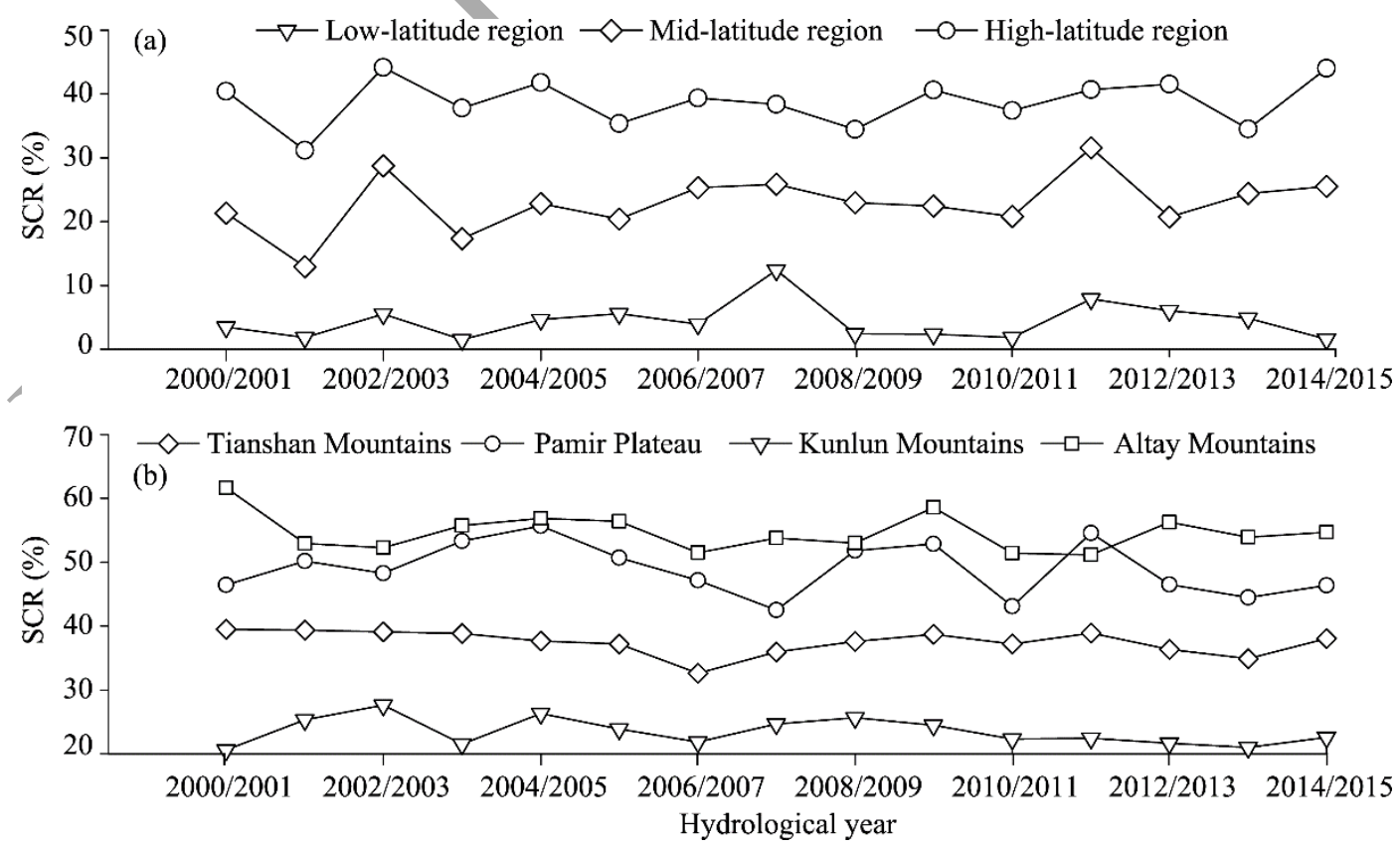

Fig. 10 Inter-annual variations of SCR in the different ecological regions of the plain areas (a) and the mountainous areas (b) 


\section{Discussion}

The overall accuracy of the cloud-free snow-cover dataset has been proven to exceed $90 \%$ by the indirect and direct validation methods. The principle of the indirect validation method is that each step of the cloud removal algorithm has its inherent accuracy (Gafurov and Bárdossy, 2009; Wang and Xie, 2009; Parajka et al., 2010; Dietz et al., 2013). The direct validation method uses high-resolution remotely sensed data (i.e., Landsat ETM + ) to validate the accuracy of the cloud-free dataset (Huang et al., 2011). The results from two evaluation methods produced a rather consistent accuracy of the cloud-free snow-cover dataset, indicating that the cloud removal algorithm presented in this study is competent to improve the quality of MODIS 8-day snow-cover products. Our results revealed a significant correlation between the SCF and latitude in the plain areas (Profile line 1) and this relationship was also confirmed by the SCR in the ecological regions, being in a good agreement with previous studies (Dietz et al., 2013). In the mountainous areas, both the SCR and SCF are related to both latitude and altitude (Guo et al., 2015; Hu et al., 2015).

The results of this study revealed that the entire Central Asia experienced a slight increasing in both SCF and SCR, indicating a winter-wetting trend over the study period 2000-2015. In the context of global warming, the averaged change rate of surface air temperature over Central Asia was $0.39^{\circ} \mathrm{C} / 10 \mathrm{a}$ in the past 30 years (Hu et al., 2014, 2015). The precipitation in Central Asia also showed an increasing trend during the period 1930-2009, particularly in winter (Chen et al., 2011; Li et al., 2011). A logic explanation is that precipitation is the predominant factor affecting the snow-cover variations and has displayed a significant increasing trend in this region (Chen et al. 2011), resulting in a remotely sensed increase in snow cover in winters primarily in low-altitude regions. The remotely-sensed data-indicated slight decrease in snow cover at high-altitude regions may be related to the observed temperature rising (Szczypta et al., 2015; Gergel et al., 2017; Huang et al., 2017).

\section{Conclusions}

Analyses on SCF and SCR were carried out to reveal the spatial and temporal variations of snow cover for the period $2000-2015$. The SCF between $39^{\circ}-54^{\circ} \mathrm{N}$ over the plain regions of Central Asia presented a north-south declining trend with a rate of approximately 0.03 per degree in latitude $\left(R^{2}=0.97, P<0.001\right)$, and the SCR showed a similar north-south gradient. However, the SCF between $37.5^{\circ}-46.5^{\circ} \mathrm{N}$ over mountainous regions revealed that the altitude was a predominant factor affecting the SCF, whereas SCR presented a positive correlation with latitude over this region. For the entire Central Asia, the SCF increased with altitude by 0.12 per kilometer with a significance level of $P<0.001$. The SCF in over approximately $65 \%$ of the study area experienced an increasing trend, although only $4.3 \%$ of the study area experienced a significant increase. The remainder (about 35\%) of the study area experienced a decreasing trend, and only $5.2 \%$ of the study area shows a statistically significant decrease trend. Both the annual SCF and SCR exhibited slight and insignificant increasing trends. These conclusions were confirmed by the first and second empirical orthogonal function (EOF) modes (EOF-1 and EOF-2). Additionally, through the analysis of the inter-annual variations of the annual mean SCR in the ecological regions, we found that the annual mean SCR in the plain areas displayed an increasing trend, but a decreasing trend was found in the mountainous areas. However, a quantitative analysis of climate change and its relationship with snow-cover variations are not performed in this study. Snow cover has an important role in the water budget and is extremely sensitive to climate change. Thus, detecting spatial and temporal variations of climate factors and their impacts on snow-cover variations will be our future research tasks.

\section{Acknowledgements}

This research was funded by the National Key Research and Development Program of China (2016YFA0602302, 
2016YFB0502502). We are thankful to Dr. Guli JIAPAER for her extremely valuable suggestions. And we also express our thanks for the data support from the National Earth System Science Data Sharing Infrastructure and the National Science and Technology Infrastructure of China (http://www.geodata.cn).

\section{References}

Ault T W, Czajkowski K P, Benko T, et al. 2006. Validation of the MODIS snow product and cloud mask using student and NWS cooperative station observations in the Lower Great Lakes Region. Remote Sensing of Environment, 105(4): 341-353.

Barry R. 2008. Snow cover. In: Sessa R, Dolman H. Terrestrial Essential Climate Variables for Climate Change Assessment, Mitigation and Adaptation. Rome: FAO, 20-21.

Brown R, Derksen C, Wang L. 2010. A multi-data set analysis of variability and change in Arctic spring snow cover extent, 1967-2008. Journal of Geophysical Research: Atmospheres, 115(D16): D16111.

Brutel-Vuilmet C, Ménégoz M, Krinner G. 2013. An analysis of present and future seasonal Northern Hemisphere land snow cover simulated by CMIP5 coupled climate models. The Cryosphere, 7(1): 67-80.

Chen F H, Huang W, Jin L Y, et al. 2011. Spatiotemporal precipitation variations in the arid Central Asia in the context of global warming. Science China Earth Sciences, 54(12): 1812-1821.

Crawford C J, Manson S M, Bauer M E, et al. 2013. Multitemporal snow cover mapping in mountainous terrain for Landsat climate data record development. Remote Sensing of Environment, 135: 224-233.

Dankers R, De Jong S M. 2004. Monitoring snow-cover dynamics in Northern Fennoscandia with SPOT VEGETATION images. International Journal of Remote Sensing, 25(15): 2933-2949.

Dietz A J, Kuenzer C, Conrad C. 2013. Snow-cover variability in central Asia between 2000 and 2011 derived from improved MODIS daily snow-cover products. International Journal of Remote Sensing, 34(11): 3879-3902.

Foppa N, Wunderle S, Hauser A, et al. 2004. Operational sub-pixel snow mapping over the Alps with NOAA AVHRR data. Annals of Glaciology, 38: 245-252.

Foster J L, Hall D K, Kelly R E J, et al. 2009. Seasonal snow extent and snow mass in South America using SMMR and SSM/I passive microwave data (1979-2006). Remote Sensing of Environment, 113(2): 291-305.

Gafurov A, Bárdossy A. 2009. Cloud removal methodology from MODIS snow cover product. Hydrology and Earth System Sciences, 13(7): 1361-1373.

Gergel D R, Nijssen B, Abatzoglou J T, et al. 2017. Effects of climate change on snowpack and fire potential in the western USA. Climatic Change, 141(2): 287-299.

Guo H, Chen S, Bao A M, et al. 2015. Inter-comparison of high-resolution satellite precipitation products over central Asia. Remote Sensing, 7(6): 7181-7211.

Hall D K, Riggs G A, Salomonson VV, et al. 2001. Algorithm theoretical basis document (ATBD) for the MODIS snow and sea ice-mapping algorithms. NASA, GSFC. https://modis.gsfc.nasa.gov/data/atbd/atbd_mod10.pdf.

Hall D K, Riggs G A, Salomonson V V, et al. 2002. MODIS snow-cover products. Remote Sensing of Environment, 83(1-2): 181-194.

Hall D K, Riggs G A. 2007. Accuracy assessment of the MODIS snow products. Hydrological Processes, 21(12): $1534-1547$.

Hu Z Y, Zhang C, Hu Q, et al. 2014. Temperature changes in central Asia from 1979 to 2011 based on multiple datasets. Journal of Climate, 27(3): 1143-1167.

Hy Z Y, Li Q X, Chen X, et al. 2015. Climate changes in temperature and precipitation extremes in an alpine grassland of Central Asia. Theoretical and Applied Climatology, 56(4): 1-13.

Huang X D, Liang T G, Zhang X T, et al. 2011. Validation of MODIS snow cover products using Landsat and ground measurements during the 2001-2005 snow seasons over northern Xinjiang, China. International Journal of Remote Sensing, 32(1): $133-152$.

Huang X D, Deng J, Wang W, et al. 2017. Impact of climate and elevation on snow cover using integrated remote sensing snow products in Tibetan Plateau. Remote Sensing of Environment, 190: 274-288.

Klein I, Gessner U, Kuenzer C. 2012. Regional land cover mapping and change detection in Central Asia using MODIS time-series. Applied Geography, 35(1-2): 219-234.

Li Q H, Chen Y N, Shen Y J, et al. 2011. Spatial and temporal trends of climate change in Xinjiang, China. Journal of Geographical Sciences, 21(6): 1007-1018.

Liang T G, Huang X D, Wu C X, et al. 2008. An application of MODIS data to snow cover monitoring in a pastoral area: a case study in Northern Xinjiang, China. Remote Sensing of Environment, 112(4): 1514-1526.

Lindzen R S, Nigam S. 1987. On the role of sea surface temperature gradients in forcing low-level winds and convergence in 
the tropics. Journal of the Atmospheric Sciences, 44(17): 2418-2436.

Lioubimtseva E, Henebry G M. 2009. Climate and environmental change in arid Central Asia: impacts, vulnerability, and adaptations. Journal of Arid Environments, 73(11): 963-977.

Liu Z F, Bowen G J, Welker J M. 2010. Atmospheric circulation is reflected in precipitation isotope gradients over the conterminous United States. Journal of Geophysical Research: Atmospheres, 115(D22): D22120.

Maurer E P, Rhoads J D, Dubayah R O, et al. 2003. Evaluation of the snow-covered area data product from MODIS. Hydrological Processes, 17(1): 59-71.

North G R, Bell T L, Cahalan R F, et al. 1982. Sampling errors in the estimation of empirical orthogonal functions. Monthly Weather Review, 110(7): 699-706.

Parajka J, Blöschl G. 2008. Spatio-temporal combination of MODIS images-potential for snow cover mapping. Water Resources Research, 440(3): W03406.

Parajka J, Pepe M, Rampini A, et al. 2010. A regional snow-line method for estimating snow cover from MODIS during cloud cover. Journal of Hydrology, 381(3-4): 203-212.

Ryu J H, Jenkins G S. 2005. Lightning-tropospheric ozone connections: EOF analysis of TCO and lightning data, Atmospheric Environment, 39(32): 5799-5805.

Singh C V. 2004. Empirical Orthogonal Function (EOF) analysis of monsoon rainfall and satellite-observed outgoing long-wave radiation for Indian monsoon: a comparative study. Meteorology and Atmospheric Physics, 85(4): $227-234$.

Szczypta C, Gascoin S, Houet T, et al. 2015. Impact of climate and land cover changes on snow cover in a small Pyrenean catchment. Journal of Hydrology, 521: 84-99.

Tang Z G, Wang J, Li H Y, et al. 2013. Spatiotemporal changes of snow cover oyer the Tibetan plateau based on cloud-removed moderate resolution imaging spectroradiometer fractional snow cover product from 2001 to 2011. Journal of Applied Remote Sensing, 7(1): 073582.

Tekeli A E, Akyürek Z, Şorman A A, et al. 2005. Using MODIS snow cover maps in modeling snowmelt runoff process in the eastern part of Turkey. Remote Sensing of Environment, 97(2): 216-230.

Wang L B, Sharp M, Brown R, et al. 2005. Evaluation of spring snow covered area depletion in the Canadian Arctic from NOAA snow charts. Remote Sensing of Environment, 95(4): 453-463.

Wang X W, Xie H J, Liang T G. 2008. Evaluation of MODIS snow cover and cloud mask and its application in Northern Xinjiang, China. Remote Sensing of Environment, 112(4): 1497-1513.

Wang X W, Xie H J. 2009. New methods for studying the spatiotemporal variation of snow cover based on combination products of MODIS Terra and Aqua. Journal of Hydrology, 371(1-4): 192-200.

Xu C C, Chen Y N, Hamid Y, et al. 2009. Long-term change of seasonal snow cover and its effects on river runoff in the Tarim River basin, northwestern China. Hydrological Processes, 23(14): 2045-2055.

Yang D Q, Zhao Y Y, Armstrong R, et al. 2007. Streamflow response to seasonal snow cover mass changes over large Siberian watersheds. Journal of Geophysical Research: Earth Surface, 112(F2): F02S22.

Yatagai A, Kamiguchi K, Arakawa O, et al. 2012. APHRODITE: constructing a long-term daily gridded precipitation dataset for Asia based on a dense network of rain gauges. Bulletin of the American Meteorological Society, 93(9): 1401-1415.

Yin G, Hu Z Y, Chen X, et al. 2016. Vegetation dynamics and its response to climate change in Central Asia. Journal of Arid Land, 8(3): 375-388.

Zhou/X B, Xie H J, Hendrickx J M H. 2005. Statistical evaluation of remotely sensed snow-cover products with constraints from streamflow and SNOTEL measurements. Remote Sensing of Environment, 94(2): 214-231. 